\title{
SPECTRUM RENTING WITH TWO FINITE SOURCE P0OLS IN MOBILE CELLULAR NETWORKS
}

Spectrum renting is a technique for improving the efficiency of spectrum usage and alleviating the scarcity of the available spectrum in mobile cellular networks. Since the first proposal of spectrum pooling, several works have been done in this area.

In this paper, we propose a finite-source queuing model in which service providers may rent each other's unutilized frequency bands. Our model contains two source pools: one for subscribers generating fresh calls in the investigated mobile cell, and another for modeling handover calls. The model considers the traveling of subscribers over the borders of the investigated mobile cell, too. Moreover, we take into account the retrial phenomenon caused by the impatience of subscribers. It has been already shown in the literature that the use of spectrum renting improves the main performance indices while the average profit rate increases. In this paper, we show how these parameters change with respect to the protection of handover calls.

Keywords: Spectrum renting, finite-source, retrial queues, handover, impatience.

\section{Introduction}

Similarly to many related research fields (see [1], [2], [3] and [4]), the efficient usage of means is always a crucial task. The basic idea of spectrum renting was first proposed by Mitola [5], to aid the efficient usage of the available radio spectrum. Since the Federal Communications Commission's Spectrum Policy Task Force [6] proposed the dynamic/liberalized access to the spectrum in 2002, many researchers have dealt with the realization of spectrum renting [7], [8], [9], [10] and [11]. Besides, some queuing models for spectrum renting were also proposed. In [12] and [13], the authors assume that the speech channels can be rented in one unit, which is not a valid assumption, since each block of speech channels should be controlled by a single network operator [14]. Do et al. considered first this technology aspect in their infinite-source model [14], but they did not consider the retrial phenomenon in their model. In [15], an opportunistic spectrum access model was proposed based on a high-level cooperation between two competing service providers (the aspects of cooperation can open new directions in this area [16]). However, the handover process and the impatience of the users were not touched in that paper.

The retrial queues have been widely studied, too, for the evaluation of the resource contention problem in mobile cellular networks. The works in this area can be classified based on the number of traffic sources. Infinite-source models were presented, e.g., in [17], [18], [19], [20] and [21], while finite-source works can be found, e.g., in [22], [23], [24], [25] and [26]. The assumption on the infinite number of sources may lead to some efficient algorithms [27]. However, the fact that the number of subscribers in a specific mobile cell is finite, justifies the construction of finite-source models. In [27], the authors proposed the use of the retrial queues to model spectrum renting. The model considers the finite size of the subscribers' population, their impatience, and has a queue for the subscribers who requested the outbound service. Moreover, the authors took the renting fee into account, too, for the optimization of the renting process. As it was mentioned in that paper, several model variants could be derived from [27] to investigate additional aspects of spectrum renting.

Based on [27], we set up a finite-source queuing model with two source pools. The additional source pool allows us to investigate also the handover calls, which were not mentioned in [27]. Moreover, our model considers the traveling of subscribers by modeling the transitions over the borders of the investigated mobile cell.

The rest of the paper is organized as follows. Section II introduces the key aspects of our model. Section III describes our system model while the mathematical background is presented in Section IV. The numerical results are provided in Section V. Finally, Section VI concludes the paper.

\footnotetext{
* ${ }^{1}$ Adam Horvath, ${ }^{2}$ Tamas Berczes

${ }^{1}$ University of West Hungary, Institute of Informatics and Economics, Sopron, Hungary

${ }^{2}$ University of Debrecen, Faculty of Informatics, Debrecen, Hungary

Email: berczes.tamas@inf.unideb.hu

Email: horvath@inf.nyme.hu
} 


\section{Background}

In this section, we give a short overview of the key aspects which we took into account in our model: the organization of speech channels, the spectrum renting, the impatience of subscribers and the handover process.

- In mobile cellular networks, service providers get exclusive access to certain frequency bands on spectrum auctions held by the government. Each service provider divides its coverage area to regular shaped cells, and assigns a number of frequency bands to each cell. Using different multiple access techniques, each frequency band hosts regularly 8 full-rate or 16 half-rate speech channels. Such techniques are the Frequency and the Time Division Multiple Access (FDMA, TDMA [28]), the Code Division Multiple Access (CDMA [29]), or for long term evolution (LTE) systems, the Orthogonal Frequency Division Multiple Access (OFDMA [30]). Therefore, a finite number of speech channels is available in each cell.

- Since the right to frequency usage is expensive, improving the utilization in mobile cellular networks is a critical task. Spectrum renting can be used for alleviating the negative effects of temporary capacity shortages [9], [14], [15]. With spectrum renting, service providers may rent each other's unutilized frequency bands to reduce the blocking probability of calls.

- As it was mentioned in the literature [14], [23] and [31], behavioral psychology of using the mobile cellular network services includes repeated attempts and abandonments. When a call is not admitted due to all channels are occupied, the subscriber initiates a repeated attempt later. The abandonment means that after a certain time, the subscribers gives up without being served.

- When the signal strength of a base station, which a traveling user is connected to, decreases below a certain value, another base station with appropriate signal strength must be chosen for serving the ongoing call. This process is termed as handover. Since the break of the connection is annoying for traveling subscribers, a protection procedure must be applied for handover calls (e.g., the well-known guard channel policy [32]).

\section{System model}

Figure 1 illustrates our system model. The model incorporates the handover process with fractional guard channel (FGC) policy, an orbit for the impatient users, and the blocks of channels, considering the own and the rented blocks, too. Moreover, the model contains two finite sources $i$ ) for generating the fresh calls within the bounds of the investigated mobile cell, and ii) for the handover calls.

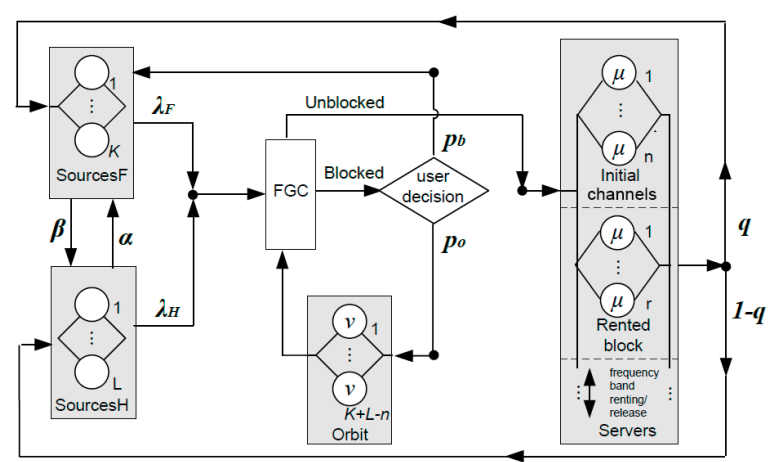

Fig. 1 The system model of the retrial queue

\section{A. Model Operation}

From the mobile cell's point of view, a finite number of $K$ subscribers belongs to one mobile cell, generating fresh calls. Being in the SourcesF state, each subscriber initiates a fresh call with rate $\lambda_{F}$.

Similarly, a finite number of $L$ subscribers belongs to the investigated mobile cell, being physically out of the cell, generating handover calls. So, the handover calls are generated from state Sources $H$ with rate $\lambda_{H}$ on the average by each subscriber.

During the idle periods, the subscribers may leave the investigated mobile cell with rate $\beta$, moving from state Sources $F$ to SourcesH. Certainly, the subscribers may move into the investigated mobile cell with rate $\alpha$, changing their state from SourcesH to SourcesF.

In order to protect the handover calls, a FGC policy is applied for the incoming calls. If a call is admitted, a channel is immediately allocated for it, either in an own frequency band, or in a rented one (state Servers in Fig. 1). The call duration is exponentially distributed with parameter $\mu$, after which the channel is released and the subscriber returns either to the SourcesF state with probability $q$, or to the SourcesH state with probability $1-q$.

If the call is not admitted, the subscriber has two options: i) he/she joins the orbit (state Orbit in Fig. 1) with probability $p_{o}$, and retries to get a free channel with retrial rate $v$, or ii) he/she gives up and becomes idle with probability $p_{b}=1-p_{o}$.

\section{B. Decision about Renting and Releasing a Frequency Band}

Do et al. proposed two thresholds for the number of free channels in [14] to determine when to rent and release frequency bands, and we apply their approach in our model. When the number of free channels decreases to a certain $t_{1}$ value, the network operator initiates the frequency renting procedure. The frequency renting is successful in our model with probability $p_{r}$, while it fails with probability $p_{f}=1-p_{r}$. In the latter case, the 
network operator retries to rent a frequency band with rate $n_{r}$ as long as the number of free channels does not exceed $t_{1}$.

On the other hand, when the number of free channels increases to $t_{2}+r$, then the block of $r$ channels are given back to the owner after an exponentially distributed release time with mean $\mu_{r}$.

To find the appropriate parameter setting, we have to take into account the blocking probability of fresh calls and handover calls, and the renting fee. To facilitate this decision, we take into account the average profit rate, too, in our investigations.

\section{Fractional Guard Channel Policies}

In order to minimize the interruption of ongoing calls network operators exclusively reserve some channels for handover calls [32]. A generalization of this concept is the FGC policy proposed in [33]. To ease the further negotiation, we collected the notations in Table 1.

Table 1

\begin{tabular}{|c|c|}
\hline Parameter & Description \\
\hline$I(t)$ & The number of occupied channels in a specific cell. \\
\hline$J(t)$ & The number of rented frequency bands. \\
\hline$\beta_{i, j}$ & $\begin{array}{l}\text { The probability of accepting a call } \\
\text { for } I(t)=i \text { and } J(t)=j \text {. }\end{array}$ \\
\hline$n$ & The number of own channels. \\
\hline$r$ & The number of channels per block. \\
\hline$N_{j}$ & $\begin{array}{l}\text { The number of available channels } \\
\left(N_{i}=n+j r \text { for } J(t)=j\right)\end{array}$ \\
\hline$g$ & The real number of guard channels. \\
\hline
\end{tabular}

Note that in case of a handover call, $\beta_{i, j}=1$. Based on [34], several FGC policy variants can be distinguished. Since Do et al. showed in [14] that the Limited average FGC (LFGC) is the most convenient for protecting handover calls, we applied this policy and the Non Prioritization Scheme (NPS) in this paper. These policies can be defined as follows [35]:

\section{- Limited average FGC ( $L F G C)$, where}

$$
\beta_{i, j}=\left\{\begin{array}{c}
1, \text { if } 0 \leq i \leq N_{j}-|g|-2 \\
1-g+|g|, \text { if } i=N_{j}-|g|-2 \\
\text { 0 else. }
\end{array}\right.
$$

- Non Prioritization Scheme (NPS), where $\beta_{i, j}=1$.

\section{Mathematical Background}

In this section, we describe the mathematical background of our work. We introduce the following notations in order to ease the further negotiation.

- $k(t)$ is the number of active sources being in the investigated mobile cell at time instant $t$,

- $l(t)$ is the number of active sources with the possibility of generating handover calls at time instant $t$,

- $s(t)$ denotes the number of occupied channels in the investigated cell at time instant $t$,

- $b(t)(0 \leq b(t) \leq m)$ is the number of rented frequency bands at time instant $t$,

- $o(t)$ is the number of calls in the orbit at time instant $t$,

- $u(t)(u(t) \in[0,1\})$ indicates whether there is an unsatisfied block rental retrial at time instant $t$.

Note that $l(t)=K+L-k(t)-s(t)-o(t)$.

In Table 2, we present the main parameters of our model while a complete list of parameters including numerical values is detailed later in Table 3 (see Section V).

Overview of the main parameters

Table 2

\begin{tabular}{|l|c|c|c|}
\hline Parameter & Maximum & $\begin{array}{c}\text { Value at } \\
\text { time } t\end{array}$ & Mean \\
\hline Nr. of users in SourcesF & $K$ & $k(t)$ & $\bar{K}$ \\
\hline Nr. of users in Sources $H$ & $L$ & $l(t)$ & $\bar{L}$ \\
\hline Orbit size & $O=K-n$ & $o(t)$ & $\bar{O}$ \\
\hline Nr. of busy channels & $n+m \times r$ & $s(t)$ & $\bar{S}$ \\
\hline Nr. of rented bands & $m$ & $b(t)$ & $\bar{B}$ \\
\hline Retrial rate of renting & 1 & $u(t)$ & $\bar{U}$ \\
\hline Fresh call gen. rate & $\lambda_{F} K$ & $\lambda_{F}$ & \\
\hline Handover call gen. rate & $\lambda_{H} L$ & $\lambda_{H}$ & \\
\hline Service rate & & $\mu$ & \\
\hline Retrial rate & & $v$ & \\
\hline Rate of leaving the cell & & $\alpha$ & \\
\hline $\begin{array}{l}\text { Rate of moving into } \\
\text { the cell }\end{array}$ & & $\beta$ & \\
\hline
\end{tabular}

To preserve the mathematical tractability, we assume that all inter-event times (including request generation time, impatience time, service time, retrial time, and times related to the spectrum renting) are exponentially distributed and can be characterized by their rate parameter ${ }^{1}$. Therefore, the system is modeled by a five-dimensional Continuous-Time Markov Chain (CTMC)

${ }^{1}$ This modeling simplification is frequently applied in the performance evaluation of wireless cellular networks, see e.g. [31], [36] or [37]. 
$\{s(t), k(t), b(t), o(t), u(t)\}$. The steady state probabilities are denoted

$$
\begin{aligned}
& p_{s, k, b, o, u}=\lim _{t \rightarrow \infty} \operatorname{Pr}(s(t)=s, k(t)= \\
& =k, b(t)=b, o(t)=o, u(t)=u)
\end{aligned}
$$

The underlying CTMC is driven by the following types of events:

a) the arrival of fresh calls and handover calls,

b) the retrials of calls,

c) the departure of calls,

d) the request and retrial process for renting spectrum,

e) the release of the rented spectrum.

Since the underlying CTMC is irreducible and its state space is finite, the steady state probabilities surely exist. Taking into account that the state space of this CTMC is very large, it is difficult to determine the performance indices of the system in a traditional way of solving the steady-state equations. Therefore, we use the MOSEL-2 software tool to generate the underlying Markov chain and its transition rate matrix directly based on a high-level model description, computing the stationary distribution, and deriving performance measures from them, such as

- mean number of rented frequency bands

$$
\bar{B}=\sum_{u=0}^{1} \sum_{b=u}^{m} \sum_{s=0}^{n+(b-u) \times r} \sum_{k=0}^{K+L} \sum_{o=0}^{K+L-n} b P(s, k, b, o, u),
$$

- mean number of busy channels

$$
\bar{S}=\sum_{u=0}^{1} \sum_{b=u}^{m} \sum_{s=0}^{n+(b-u) \times r} \sum_{k=0}^{K+L} \sum_{o=0}^{K+L-n} s P(s, k, b, o, u)
$$

- mean orbit size

$$
\bar{O}=\sum_{u=0}^{1} \sum_{b=u}^{m} \sum_{s=0}^{n+(b-u) \times r} \sum_{k=0}^{K+L} \sum_{o=0}^{K+L-n} o P(s, k, b, o, u),
$$

- mean number of sources generating fresh calls

$$
\bar{K}=\sum_{u=0}^{1} \sum_{b=u}^{m} \sum_{s=0}^{n+(b-u) \times r} \sum_{k=0}^{K+L} \sum_{o=0}^{K+L-n} k P(s, k, b, o, u),
$$

- mean number of sources generating handover calls

$$
\bar{L}=K+L-\bar{S}-\bar{K}-\bar{O} \text {, }
$$

- mean system throughput $\bar{\lambda}=(\bar{K}+\bar{L}) \lambda$,

- mean time spent in the orbit

$$
\overline{T_{O}}=\frac{\bar{O}}{\bar{\lambda}}
$$

The last equation can be derived as follows. Let $\lambda_{O}$ denote the throughput of the orbit. Using Little's Low, the mean time spent in the orbit by each request is $\overline{T_{O}^{v}}=\frac{\bar{O}}{\lambda_{O}}$. The mean number of visits in the orbit by each request is $e_{O}=\frac{\lambda_{O}}{\bar{\lambda}}$. So the overall mean time spent in the orbit can be computed as

$\overline{T_{O}}=e_{o} \overline{T_{O}^{v}}=\frac{\lambda_{o}}{\bar{\lambda}} \frac{\bar{O}}{\lambda_{o}}=\frac{\bar{O}}{\bar{\lambda}}$.

\section{Numerical results}

The MOSEL-2 tool uses a high-level modeling language that provides a very convenient way for system description [38]. It focuses on the formal system description and exploits the power of various existing and well-tested packages (MOSES [39], SPNP [40] and [41] and TimeNET [42]) for numerical evaluation.

In Table 3, we collected the parameter settings we used in our investigations. As we mentioned above, we use the exponential distribution for modeling the channel holding times, which follow the lognormal distribution [43]. To get a mathematically tractable model, we also used the exponential distribution for channel holding times with the mean of 53.22s, which was determined observing real data traffic [43].

The applied parameter setting

Table 3

\begin{tabular}{|l|c|c|}
\hline Parameter & Symbol & Value \\
\hline Normalized traffic intensity & $\rho_{0}=\frac{K \lambda}{n \mu}$ & {$[0.1 \ldots 0.9]$} \\
\hline Fresh call generation rate & $\lambda_{F}$ & $\frac{2}{3} \lambda$ \\
\hline Handover call generation rate & $\lambda_{H}$ & $\frac{1}{3} \lambda$ \\
\hline Initial nr. of subscribers in SourcesF & $K$ & 100 \\
\hline Initial nr. of subscribers in SourcesH & $L$ & 50 \\
\hline Real number of reserved channels & $g$ & 2.9 \\
\hline Retrial rate & $v$ & 1 \\
\hline Prob. that subscriber gives up & $p_{b}$ & 0.5 \\
\hline Impatience rate & $\eta$ & $1 / 300$ \\
\hline Prob. that imp. user goes back to orbit & $p_{O}$ & 0.5 \\
\hline No. of channels per block & $r$ & 8 \\
\hline Number of channels without renting & $n$ & $2 \times r$ \\
\hline Service rate & $\mu$ & $1 / 53.22$ \\
\hline Rate of moving into the cell & $\alpha$ & 0.45 \\
\hline Rate of leaving the cell & $\beta$ & 0.55 \\
\hline Block renting threshold & $t_{1}$ & 3 \\
\hline Block renting rate & $\lambda_{r}$ & 0.2 \\
\hline Block release threshold & $t_{2}$ & 6 \\
\hline Block release rate & $\mu_{r}$ & 1 \\
\hline Prob. for successful renting & $p_{r}$ & 0.8 \\
\hline Block rental retrial rate & & $1 / 7$ \\
\hline
\end{tabular}


In the following figures, we depict the results applying LFGC policy for protecting the handover calls, and the case when no protection was applied (NPS). Moreover, Figures 2 - 5 show the results besides the use of spectrum renting, and the no renting case, when $p_{r}=0$. The results clearly show that the possibility of spectrum renting significantly decreases the blocking probabilities. Accordingly, the mean orbit size also decreases applying spectrum renting. Finally, the use of spectrum renting increases the average profit rate (APR), which is an evident financial advantage.

In the following, we focus on the results concerning the handover calls' protection since touching this aspect is a remarkable novelty in our contribution.

Figures 2 and 3 show the blocking probabilities of fresh and handover calls, respectively, as a function of the normalized traffic intensity. We can observe that applying LFGC policy, we obtain an increased protection for handover calls while the price of this protection is the increased blocking probability of fresh calls compared to the case when NPS is used.

In Fig. 4, the mean orbit size in shown. Since the subscribers rapidly leave this state (either due to retrial or giving up), the number of subscribers is relatively low in the orbit even if the traffic increases. Due to the increased blocking probability caused by protecting handover calls, the mean orbit size is higher when LFGC policy was applied than in case of NPS.

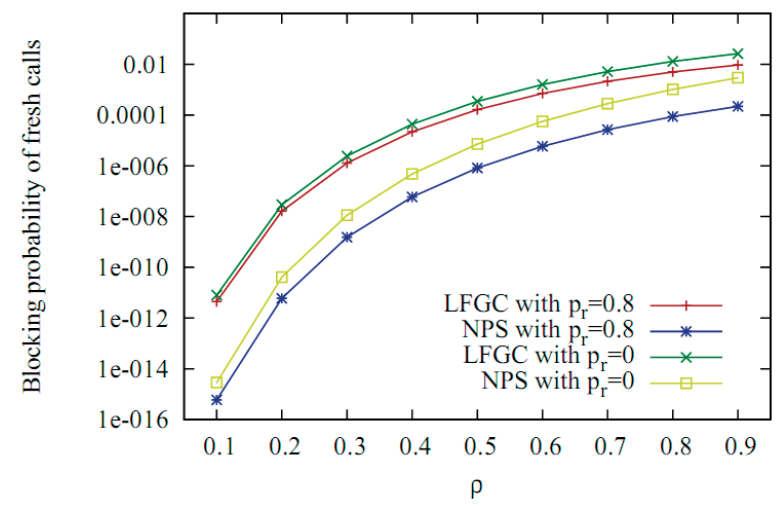

Fig. 2 Blocking probability of fresh calls as a function of the normalized traffic intensity

To measure the financial effect of the handover calls' protection, we illustrated the APR as a function of the normalized traffic in Fig. 5. Besides the case of NPS, we depicted two graphs with different values of LFGC parameter $g$. We can realize that protecting the handover calls has little impact on APR when number of guard channels is 2.9. Using $g=6.3$, the difference between the investigated policies becomes significant as the normalized load increases (the protection of handover calls with relatively high number of guard channels must be paid). However, the operators are able to fine-tune the value of $g$ in view of the expected profit, too.

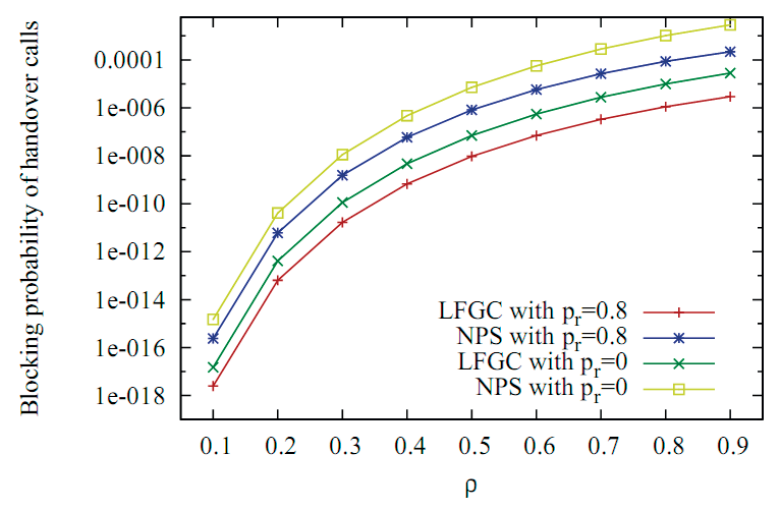

Fig. 3 Blocking probability of handover calls as a function of the normalized traffic intensity

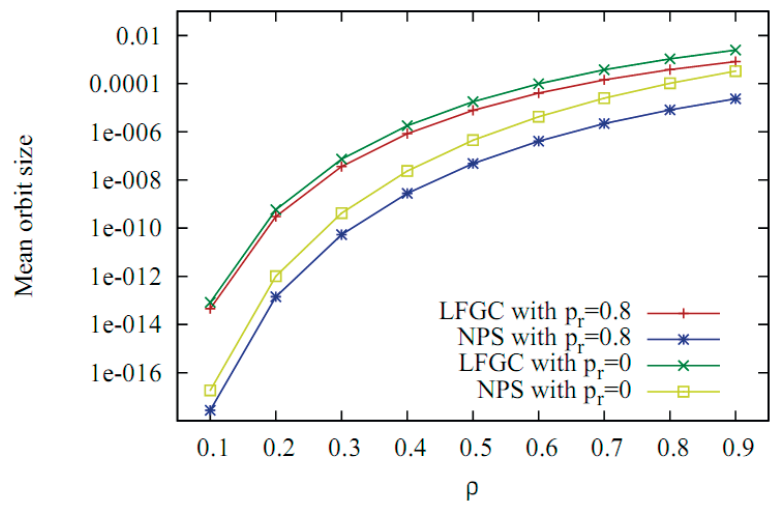

Fig. 4 The mean orbit size as a function of the normalized traffic intensity

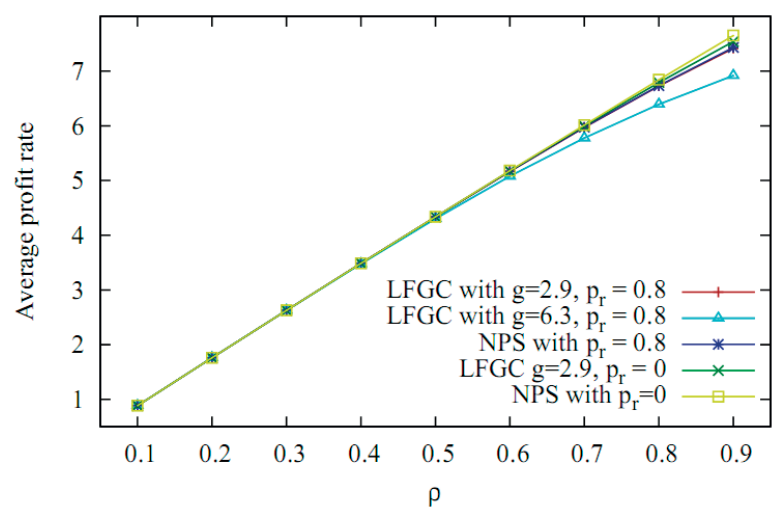

Fig. 5 The average profit rate as a function of the normalized traffic intensity 
For the more precise investigation of LFGC parameter $g$, we investigated the above mentioned performance indices as a function of $g$ (see Figs. 6 - 9). To ease the comparison with the case of NPS, we also represent the constant values of NPS policy in Figures 6 - 9. As we can see in Figs. 6 and 7, the operators should find a trade-off between the blocking probabilities of fresh calls and handover calls, while the effect of the value of $g$ on the APR is not significant in this scenario until $g$ increases to around 4 (Fig. 9).

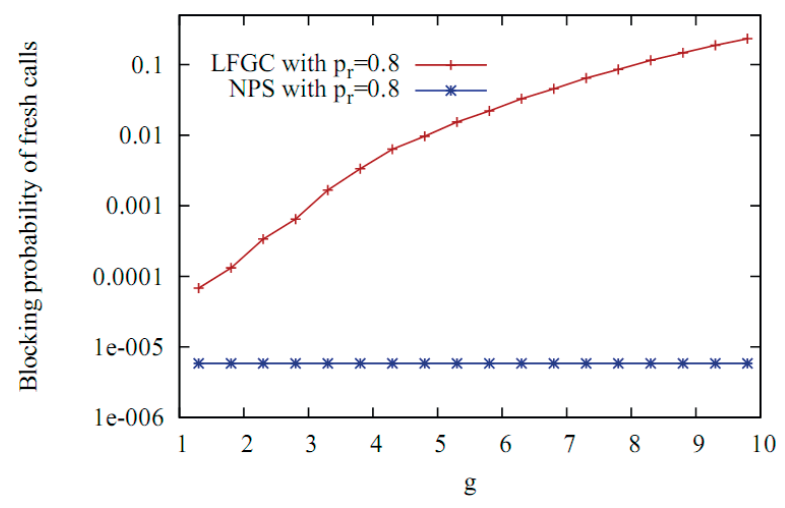

Fig. 6 The blocking probability of fresh calls as a function of the number of guard channels

\section{Conclusions}

In this paper, we described a queuing model with finite number of subscribers for modeling spectrum renting. The results showed that applying spectrum renting, the blocking probabilities decrease while the increasing value of APR justifies the financial benefits of spectrum renting. To the best of our knowledge, our model is the first finite-source queuing model for modeling spectrum renting in wireless cellular networks that incorporates the handling of handover calls' protection, together with modeling the subscribers' mobility and the retrial phenomenon caused by the impatience of subscribers. Our investigations showed that with appropriate parameter setting, the mobile operators can make a trade-off between the blocking probability of fresh calls and handover calls while the average profit rate can be preserved by controlling the number of guard channels.

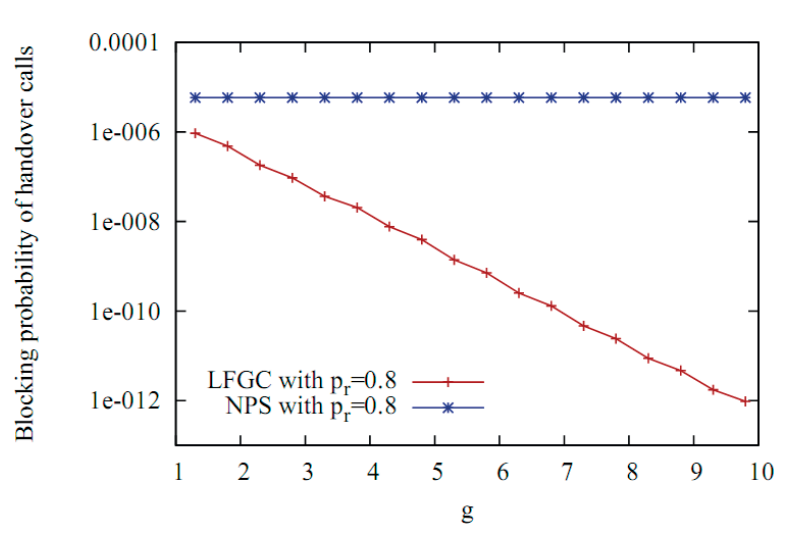

Fig. 7 The blocking probability of handover calls as a function of the number of guard channels

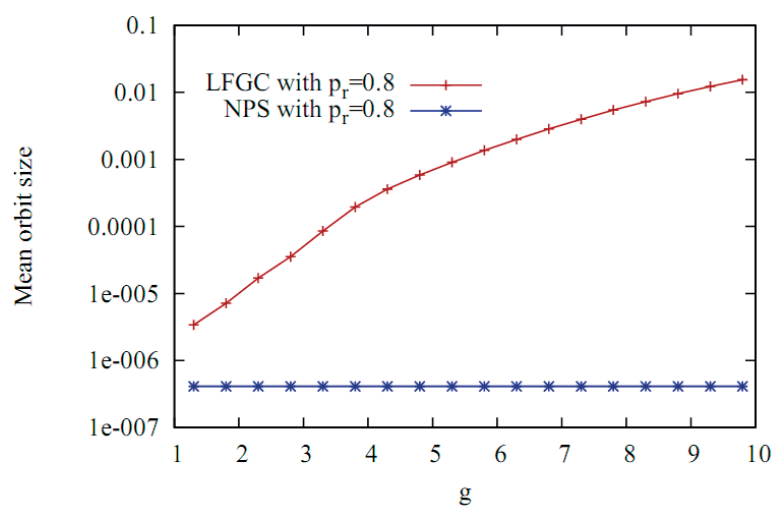

Fig. 8 The mean orbit size as a function of the number of guard channels

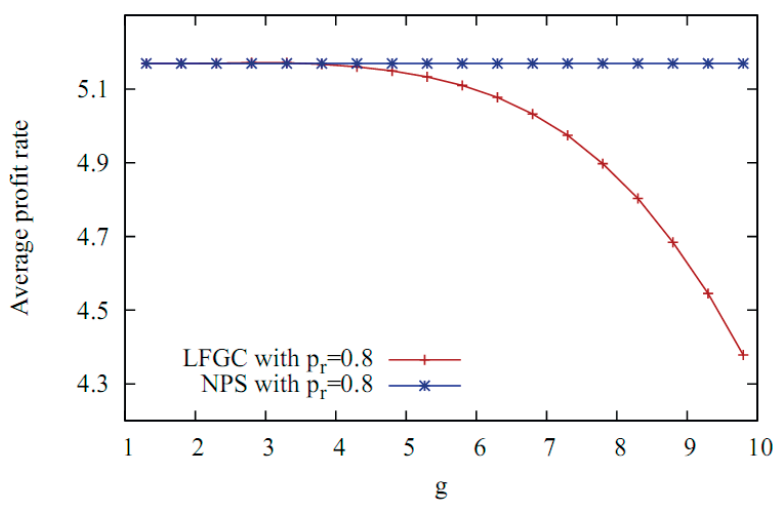

Fig. 9 The average profit rate as a function of the number of guard channels

\section{Acknowledgment}

The authors thank Prof. Tien Van Do, Department of Networked Systems and Services, Budapest University of 
Technology and Economics, for his professional support during the preparation of this paper.

The work of Tamas Berczes was supported by the TAMOP 4.2.2. C11/1/KONV20120001 project. The project has been supported by the European Union, co-financed by the European Social Fund.
The research of Adam Horvath was supported by the European Union and the State of Hungary, co-financed by the European Social Fund in the framework of TAMOP 4.2.4. A/211120120001 "National Excellence Program".

\section{References}

[1] RADOS, I., SCHWARTZ, L.: The Worst Availability as a Parameter for Designing and Reporting on the Network Performances, Communications - Scientific Letters of the University of Zilina, vol. 13, No. 1, pp. 60-66, 2011.

[2] LYKOURGIOTIS, A., KOTSOPOUlOS, S.: Protocols Performance in Next Generation Networks, Communications - Scientific Letters of the University of Zilina, vol. 13, No. 2A, pp. 13-18, 2011.

[3] CHEN, Y., HALBAUER, H., SAUR, S., SCHAICH, F.: WiMax Performance Impacts in Multi-cell Deployments, Communications - Scientific Letters of the University of Zilina, vol. 10, No. 4, 2008.

[4] VARDAKAS, J. S., VASSILAKIS, V. G, LOGOTHETIS, M. D.: Performance Modeling and Analysis of Passive Optical Networks for Poisson Traffic, Communications - Scientific Letters of the University of Zilina, vol. 10, no. 4, pp. 38-44, 2008.

[5] MITOLA, J. III: Cognitive Radio for Flexible Mobile Multimedia Communications, Mobile Multimedia Communications, MoMuC'99 - IEEE Intern. Workshop, pp. 3-10, IEEE, 1999.

[6] KOLODZY, P.: Spectrum Policy Task Force, Communications, docket No. 02-135, 2002.

[7] BUDDHIKOT, M. M.: Understanding Dynamic Spectrum Access: Models, Taxonomy and Challenges, 2nd IEEE Intern. Symposium on New Frontiers in Dynamic Spectrum Access Networks, DySPAN 2007, pp. 649-663, 2007.

[8] GANDHI, S., BURAGOHAIN, C., CAO, L., ZHENG, H., SURI, S.: Towards Realtime Dynamic Spectrum Auctions, Computer Networks, vol. 52, No. 4, pp. 879-897, 2008.

[9] PEHA, J. M.: Sharing Spectrum through Spectrum Preform and Cognitive Radio, Proc. of the IEEE, vol. 97, pp. 708-719, 2009.

[10] JABBARI, B., PICKHOLTZ, R., NORTON, M.: Dynamic Spectrum Access and Management Dynamic SpectrumM, IEEE Wireless Communications, vol. 17, pp. 615, aug. 2010.

[11] WEISS, T. A., JONDRAL, F.: Spectrum Pooling: An Innovative Strategy for the Enhancement of Spectrum Efficiency, IEEE Communications Magazine, vol. 42, pp. 8-14, March 2004.

[12] TZENG, S.-S.: Call Admission Control Policies in Cellular Wireless Networks with Spectrum Renting, Computer Communications, vol. 32, No. 18, pp. 1905-1913, 2009.

[13] TZENG, S.-S., HUANG, C.-W.: Threshold Based Call Admission Control for QoS Provisioning in Cellular Wireless Networks with Spectrum Renting, Novel Algorithms and Techniques in Telecommunications and Networking, pp. 17-22, Springer: Berlin: Heidelberg, 2010

[14] DO, T. V., DO, N. H., CHAKKA, R.: A New Queueing Model for Spectrum Renting in Mobile Cellular Networks, Computer Communications, vol. 35, No. 10, pp. 1165-1171, 2012.

[15] HORVATH, A.: Applying Opportunistic Spectrum Access in Mobile Cellular Networks, Infocommunications J., vol. 5, No. 2, pp. 36-40, 2013.

[16] VODAK, J., SOVIAR, J., LENDEL, V.: Identification of the Main Aspects of Cooperation Management and the Problems Arising from their Misunderstanding," Communications - Scientific Letters of the University of Zilina, vol. 16, No. 3, pp. 93-101, 2014.

[17] MARSAN, M. A., CAROLIS, G. D., LEONARDI, E., LO CIGNO, R., MEO, M.: Efficient Estimation of Call Blocking Probabilities in Cellular Mobile Telephony Networks with Customer Retrials, IEEE J. on Selected Areas in Communications, vol. 19, No. 2, pp. 332-346, 2001.

[18] ARTALEJO, J. R.: Accessible Bibliography on Retrial Queues: Progress in 2000-2009, Mathematical and Computer Modelling, vol. 51, no. 9-10, pp. 1071-1081, 2010.

[19] DO, T. V.: An Efficient Solution to a Retrial Queue for the Performability Evaluation of DHCP, Computers \& OR, vol. 37, No. 7, pp. 1191-1198, 2010.

[20] DO, T. V.: A New Computational Algorithm for Retrial Queues to Cellular Mobile Systems with Guard Channels, Computers \& Industrial Engineering, vol. 59, No. 4, pp. 865-872, 2010. 
[21] TRAN-GIA, P., MANDJES, M.: Modeling of Customer Retrial Phenomenon in Cellular Mobile Networks, IEEE J. on Selected Areas in Communications, vol. 15, No. 8, pp. 1406-1414, 1997.

[22] ARTALEJO, J. R., LOPEZ-HERRERO, M. J.: The Single Server Retrial Queue with Finite Population: A BSDE Approach, Operational Research, vol. 12, No. 2, pp. 109-131, 2012.

[23] WUECHNER, P., SZTRIK, J., DE MEER, H.: Finite-source M/M/S Retrial Queue with Search for Balking and Impatient Customers from the Orbit, Computer Networks, vol. 53, No. 8, pp. 1264-1273, 2009.

[24] ZHANG, F., WANG, J.: Stochastic Analysis of a Finite Source Retrial Queue with Spares and Orbit Search, Measurement, Modelling, and Evaluation of Computing Systems and Dependability and Fault Tolerance, No. 7201 of Lecture Notes in Computer Science, pp. 1630, Springer, 2012.

[25] GHARBI, N., DUTHEILLET, C.: An Algorithmic Approach for Analysis of Finite-source Retrial Systems with Unreliable Servers, Computers \& Mathematics with Applications, vol. 62, No. 6, pp. 2535-2546, 2011.

[26] ALMASI, B., ROSZIK, J., SZTRIK, J.: Homogeneous Finite-source Retrial Queues with Server Subject to Breakdowns and Repairs, Mathematical and Computer Modelling, vol. 42, No. 5-6, pp. 673-682, 2005.

[27] DO, T. V., WUECHNER, P., BERCZES, T., SZTRIK, J., MEER, H. D.: A New Finite-Source Queueing Model for Mobile Cellular Networks Applying Spectrum Renting, Asia Pacific J. of Operational Research (APJOR), vol. 31, No. 2, 2013.

[28] Y.-B. LIN and I. CHLAMTAC, Wireless and Mobile Network Architectures, Wiley Computer Publishing, John Wiley \& Sons, Inc., 2001.

[29] RAPPAPORT, T. S.: Wireless Communications, Principles and Practice, Prentice-Hall, 2002.

[30] COX, C.: Orthogonal Frequency Division Multiple Access, in An Introduction to LTE: LTE, LTE-Advanced, SAE and 4G Mobile Communications, John Wiley \& Sons, Ltd, Chichester, UK. 2012.

[31] PEREL, N., YECHIALI, U.: Queues with Slow Servers and Impatient Customers, European J. of Operational Research, vol. 201, No. 1, pp. 247-258, 2010.

[32] GUERIN, R.: Queueing-blocking System with Two Arrival Streams and Guard Channels, IEEE Transactions on Communications, vol. 36, No. 2, pp. 153-163, 1988.

[33] RAMJEE, R., TOWSLEY, D., NAGARAJAN, R.: On Optimal Call Admission Control in Cellular Networks, Wireless Networks, vol. 3, No. 1, pp. 29-41, March 1997.

[34] CRUZ-PEREZ, F. A., ORTIGOZA-GUERRERO, L.: Fractional Resource Reservation in Mobile Cellular Systems, Resource, Mobility, and Security Management in Wireless Networks and Mobile Communications, pp. 335-362, Oct 2006.

[35] DO, T. V.: Solution for a Retrial Queueing Problem in Cellular Networks with the Fractional Guard Channel Policy, Mathematical and Computer Modelling, vol. 53, No. 11-12, pp. 2058-2065, 2011.

[36] ARTALEJO, J. R., GOMEZ-CORRAL, A.: Retrial Queueing Systems: A Computational Approach, Springer, 2008.

[37] TRAN-GIA, P., MANDJES, M.: Modeling of Customer Retrial Phenomenon in Cellular Mobile Networks, IEEE J. of Selected Areas in Communications, vol. 15, pp. 14061414, 1997.

[38] WUECHNER, P., DE MEER, H., BARNER, J., BOLCH, G.: A Brief Introduction to MOSEL-2, Proc. of MMB 2006 Conference, University of Erlangen, VDE Verlag, 2006.

[39] GREINER, S., BOLCH, G.: Modeling Production Lines with Blocking, Batch Processing and Unreliable Machines Using the Markov Analyzer MOSES, Proc. European Simulation Symp. - ESS '95, pp. 303-309, 1995.

[40] CIARDO, G., MUPPALA, J. K., TRIVEDI, K. S.: SPNP: Stochastic Petri Net Package, PNPM, pp. 142-151, IEEE Computer Society, 1989.

[41] HIREL, C., TUFFIN, B., TRIVEDI, K. S.: SPNP: Stochastic Petri Nets. Version 6.0, Proc. of the 11th Intern. Conference on Computer Performance Evaluation: Modelling Techniques and Tools, pp. 354-357, Springer-Verlag, London, UK, 2000.

[42] GERMAN, R., KELling, C., ZIMMERMANN, A., HOMMEL, G., BERLIN, T. U., ROBOTIK, F. P. U.: TimeNET - A Toolkit for Evaluating Non-Markovian Stochastic Petri Nets, Performance Evaluation, vol. 24, pp. 69-87, 1995.

[43] JEDRZYCKI, C., LEUNG, V.: Probability Distribution of Channel Holding Time in Cellular Telephony Systems, Vehicular Technology Conference, 1996. 'Mobile Technology for the Human Race', IEEE $46^{\text {th }}, 1996$. 